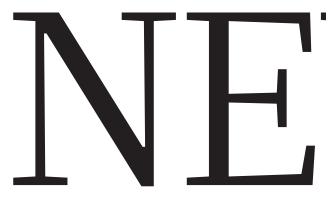

RESEARCH European centre aims to turn sea creatures into lab workhorses p.444
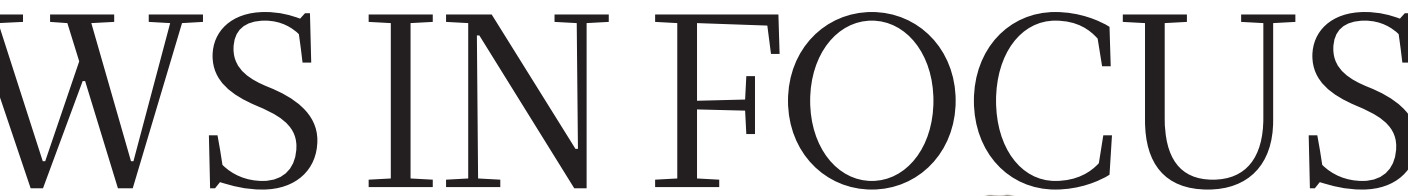

BUSINESS When big pharma swallows a biotech, can innovation survive? p.449
Q\&A A veteran of US climate policy reflects on battles still to come $\mathbf{p . 4 5 1}$
ANIMAL RESEARCH Nature

survey reveals widespread harassment. p.452

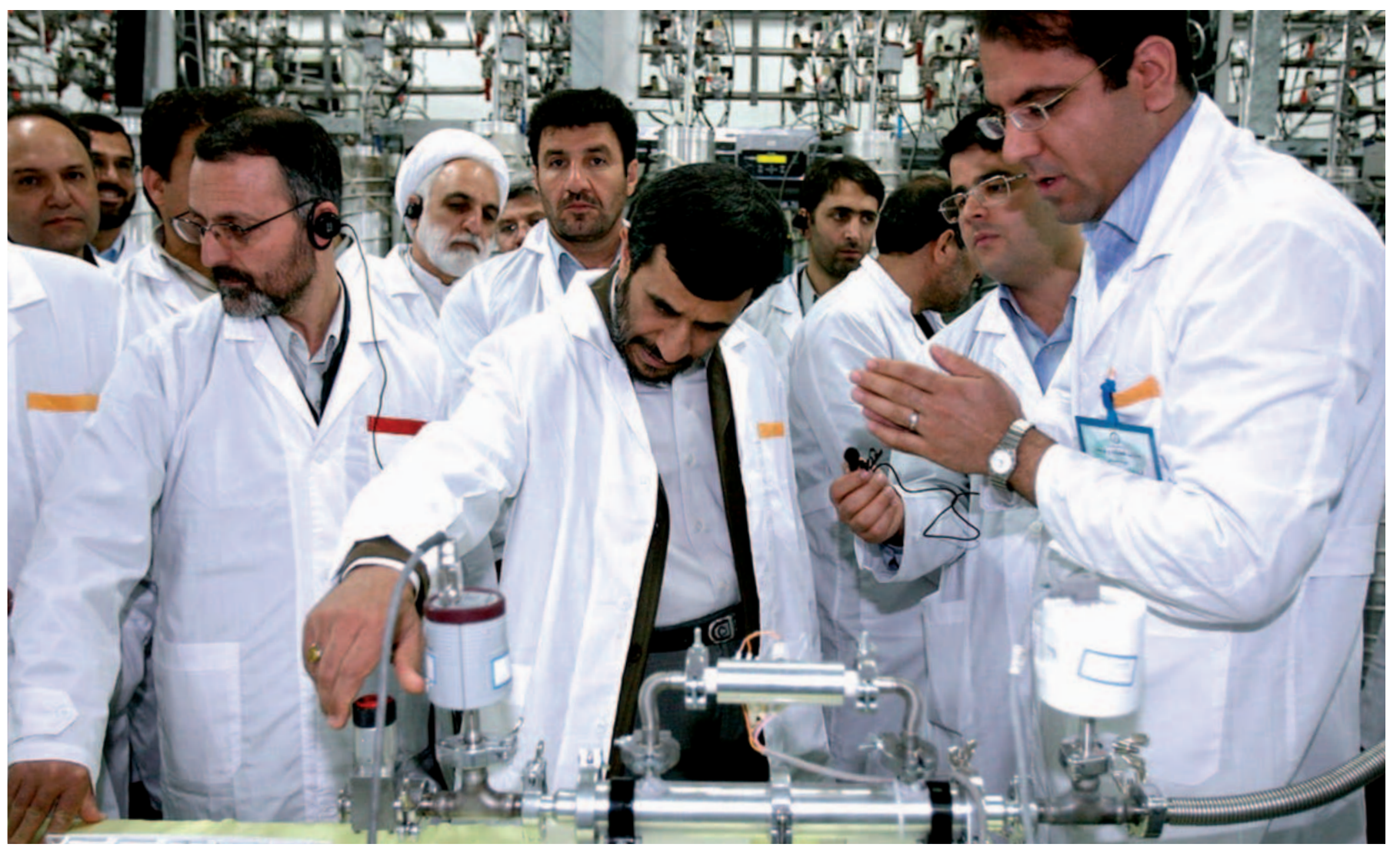

Iranian President Mahmoud Ahmadinejad (centre) visiting the Natanz nuclear enrichment facility.

\title{
Clash over Iran's capability
}

\section{Effects of sanctions and computer worm on uranium production are disputed.}

\section{BY SHARON WEINBERGER}

$\mathrm{E}$ xperts at two prominent organiza1 tions are clashing over whether Iran is improving its uranium enrichment capability, a key measure of its ability to produce a nuclear weapon.

On one side is David Albright, president of the Institute for Science and International Security (ISIS) in Washington DC, and a widely quoted authority on Iran's nuclear programme. In a report (go.nature.com/5rgzpa) released by ISIS on 15 February, Albright and his co-authors find that the Stuxnet computer worm - a computer program that hit many industrial systems in 2009 and 2010, and is widely thought to have been targeted at Iran's nuclear programme - probably destroyed about 1,000 centrifuges located at a fuel enrichment plant at Natanz, in central Iran. "It set them back," Albright told US television personality Stephen Colbert in an interview, echoing the US government's optimism.

Just a few weeks before, however, an analysis (go.nature.com/sihqyl) published by Ivanka Barzashka, a physicist then working at the Federation of American Scientists (FAS), also in Washington DC, came to a very different conclusion. It is impossible to estimate the effect of Stuxnet on Iran's nuclear programme, and more to the point, Iran's centrifuges are, on average, performing much better than the previous year, the report says. The ISIS assumption about Stuxnet destroying centrifuges "can lead to dangerous conclusions, such as that we are slowing down Iran's programme, and that gives you a sense of complacency", says Barzashka, now a visiting scholar at the Bulgarian Academy of Sciences, Sofia.

The technical debate between the FAS and ISIS centres on the effectiveness of Iran's IR-1 centrifuges, the fast spinning machines that 
- separate uranium-235 from the heavier uranium-238 isotope. A number of outside organizations, including the FAS and ISIS, have focused on how efficiently those centrifuges can enrich uranium, measured as kilograms of enriched uranium produced per standard 'separative work unit' (kg SWU). This number would help indicate how quickly Iran, if it so chose, could enrich enough material for a nuclear weapon.

Barzashka bases her derivation of SWU on data provided by the International Atomic Energy Agency (IAEA), which conducts regular inspections of Iran's nuclear facilities. On the basis of those numbers, she estimates that Iran's ability to enrich uranium is increasing. This suggests that Stuxnet has not been as detrimental as Albright suggests, and that Iran has actually improved its overall efficiency with centrifuges.

The FAS entered the debate in 2009 (see 'Spinning the numbers') when Barzashka and Ivan Oelrich, a retired senior fellow at the FAS, using publicly available IAEA numbers, calculated Iran's centrifuge performance as around $0.44 \mathrm{~kg}$ SWU per year. Using the same methods, Barzashka's latest analysis finds $0.77 \mathrm{~kg}$ SWU per year. Both numbers are lower than those of ISIS, and lower than many other independent estimates. But Barzashka maintains that just as others were overestimating Iran's capabilities in the past, they are now perhaps overestimating the effect of the Stuxnet worm and ignoring evidence that Iran's capabilities are actually improving.

\section{SPINNNGG THE NUMBERS}

Estimates of Iran's pace of uranium enrichment have varied over time. Figures seem to converge but there is uncertainty about the facts behind the trend.

\begin{tabular}{ccl}
\multicolumn{2}{c}{ kg SWU/yr } & Source \\
\hline 16 MAY 2006 & 1.46 & $\begin{array}{l}\text { Jeffrey Lewis } \\
\text { go.nature.com/izqsmj }\end{array}$ \\
\hline 1 NOV 2007 & 2 & $\begin{array}{l}\text { David Albright } \\
\text { go.nature.com/ghrzfv }\end{array}$ \\
\hline 17 JAN 2008 & 1.36 & $\begin{array}{l}\text { Richard Garwin } \\
\text { go.nature.com/4psvtc }\end{array}$ \\
\hline 27 FEB 2009 & 2.2 & go.nature.com/ghrzfv \\
\hline 22 SEP 2009 & 2.1 & $\begin{array}{l}\text { Ali Akbar Salehi } \\
\text { go.nature.com/wp4kxs }\end{array}$ \\
\hline 25 SEP 2009 & 0.44 & $\begin{array}{l}\text { Ivan Oelrich \& } \\
\text { Ivanka Barzashka } \\
\text { go.nature.com/vnuhzz }\end{array}$ \\
\hline 21 JAN 2011 & 0.77 & $\begin{array}{l}\text { Ivanka Barzashka } \\
\text { go.nature.com/sihqyl }\end{array}$ \\
\hline 15 FEB 2011 & 0.9 & $\begin{array}{l}\text { David Albright et al. } \\
\text { go.nature.com/5rgzpa }\end{array}$ \\
\hline
\end{tabular}

Albright now places Iran's enrichment capacity at $0.9 \mathrm{~kg}$ SWU per year, partly on the basis of government information that is not available to other experts. This is a downward trend relative to earlier numbers from ISIS, but despite the fact the two groups' numbers seem to be converging, the conclusions that they draw from those numbers have continued to fuel an acrimonious debate.

In December 2010, Albright e-mailed the head of the FAS, calling Oelrich and
Barzashka's Iran estimates a "bogus claim”. Oelrich and Barzashka - their departures from the FAS were unrelated to the matter disagree. "Albright doesn't assume any value, he bases his value on expert opinion," says Oelrich. "And we don't assume any value; we calculate it based on IAEA results."

Albright says that if Iran were to pursue a nuclear weapon at full speed, it would take the country only about six months to enrich a sufficient quantity of uranium at Natanz. The Obama administration, according to Albright, uses a more conservative estimate of 10-14 months. Barzashka's latest estimate of five months is in close agreement with Albright.

Barzashka says that, in such a 'breakout scenario' of full-speed production, underestimating Iran's progress "takes away from the urgency of a diplomatic breakthrough".

But for some, the absolute numbers matter less than the debate itself. "The one thing we've learned from the Iraq debacle is that you have to have technical debates; everyone's assumptions have to be challenged," says Jacqueline Shire, a member of the United Nations Panel of Experts, which looks at the effectiveness of sanctions against Iran.

Shire, who used to work at ISIS, warns that getting "bogged down in SWU numbers" can also divert attention from the real issue. "One can very easily start to get buried in minutiae and lose sight of the big picture," she says, "which is to stop Iran from enriching uranium, and think creatively about how to do that." -

\section{Marine biology network launches into choppy waters}

\section{Ambitious European project hopes to navigate uncertain funding future.}

\section{BY NICOLA NOSENGO}

Oometimes good ideas take a while to be picked up. In 1872, Anton Dohrn, a $\checkmark$ pioneering German biologist, wrote a commentary in Nature proposing the foundation of "a net of scientific stations" along European coasts, focusing on marine biology (Nature $5,277-280 ; 1872)$. Almost 140 years later, an institute that bears Dohrn's name is leading a twenty-first-century realization of his idea.

The European Marine Biological Resource Centre (EMBRC) will launch this week at a meeting in Naples, Italy, with the Anton Dohrn Zoological Station in Naples (SZN) taking the lead. Linking 15 existing research centres in 8 countries (see 'Marine network'), the project will create an overarching organization for
European research on marine biology, and provide model organisms for studying fundamental molecular biology and for screening drug candidates, for example. But the project has yet to secure the ambitious budget needed to realize its full potential.

Its goal is to make experiments on marine organisms as easy and common as those on mice or fruitflies. "Most of the molecular biology we know today comes from terrestrial species," says SZN president Roberto di Lauro. "Genetics has mostly focused on Drosophila or the mouse because they are very easy to grow in a lab." Yet, he points out, most of the world's genetic diversity is found at sea, and some marine species are becoming useful model organisms. The sea squirt Ciona intestinalis, for example, is one of the closest invertebrate

relatives of humans and has had its genome sequenced, making it useful for a range of studies. Interest in marine organisms such as Ciona is growing rapidly outside the community of marine ecologists.

The EMBRC aims to select a few species as the best candidates to become model organisms and develop technologies to grow them in artificial seawater, and to study and modify their genes. These organisms will be made available to other institutes or companies, along with the technology and sup-

$\rightarrow$ NATURE.COM To read Anton Dohrn's original vision, see: go.nature.com/Wel8cN port needed to study them. The centre could also produce strains of genetically modified organisms on request for institutes that want 